\title{
New trends in under-five mortality determinants and their effects on child survival in Nigeria: A review of childhood mortality data from 1990-2008
}

\author{
Joshua O. Akinyemi ${ }^{1+}$, E. Afolabi Bamgboye ${ }^{1}$ and Olusola Ayeni ${ }^{1}$ \\ ${ }^{1}$ Department of Epidemiology and Medical Statistics, Faculty of Public Health, College of Medicine, \\ University of Ibadan, Ibadan, Nigeria.
}

\begin{abstract}
Under-five mortality in Nigeria has been reported to be on the decline, but the dynamics are yet to receive adequate attention. Thus the main objective of this study was to assess these factors and quantify their relative contributions to under-five mortality between 1990 and 2008. The Nigeria Demographic and Health Survey data for 1990, 2003 and 2008 were re-analysed to assess the trends in determinants of under-fivemortality. Cox Regression model was applied to determine the relative contributions of each factor to the under-five mortality risk. The results showed there were improvements in maternal education (8.6\%), childhood vaccination (I7.7\%), use of oral rehydration therapy (13.9\%) and medical treatment of childhood illnesses (I7.5\%) over the 19-year period. There were declines in proportions with birth interval less than 24 months (3.9\%), access to improved sources of drinking water (24.2\%), improved toilet facilities (9.0\%) antenatal care (4.5\%), skilled delivery (3.0\%) while maternal age at childbirth remained unchanged. These factors increased the death hazards by $4.6 \%$ between 1990-2003 but decreased them by $12 \%$ between 2003 and 2008. It was concluded that Nigeria has recorded very minimal improvements in birth spacing and antenatal/delivery care. Poor access to potable drinking water and sewage disposal, and short birth intervals, are among the factors fuelling childhood mortality risks. Further improvements in these environmental and health practices as well as other factors are recommended as strategies for promoting child survival in Nigeria.
\end{abstract}

Keywords: Under-five mortality, determinants, trends, effects, Nigeria

\section{Introduction}

Recent reports have revealed an annual global decline of $2.2 \%$ in childhood mortality between 1990 and 2010 (Rajaratnam et al. 2010). However, this observed rate of decline falls short of the estimated $4.4 \%$ needed to achieve the $4^{\text {th }}$ Millennium Development Goal (MDG 4) globally. The trend in under-five mortality varied from one region of the world to another over the decades. Murray et al. (2007) estimated that worldwide under-five mortality declined from 89.1 per 1000 in 1990 to 72.3 per 1000 in 2005. Within the same period, West Africa under-five mortality ranged from 187 to 172 per 1000 live births. Consistent decline was recorded in several regions in Europe, Latin America and South East Asia while sub-Saharan Africa was dominated by slow progress (Murray et al. 2007). In the 1990s, Africa had the poorest progress in childhood mortality reduction (Ahmad et al. 2000). However, African countries such as Botswana, Ethiopia, Malawi and Togo experienced a steady decline during the period. Some others such as Namibia, South Africa, Kenya and Zimbabwe experienced some periods of exces- sive childhood mortality due to the upsurge in the HIV/AIDS epidemic (Garenne and Gakusi, 2006). It is however encouraging that decline has since been accelerated in sub-Saharan Africa between 2000 and 2010 (Rajaratnam, 2010).

Nigeria, the largest country in the West Africa sub-region, with an estimated population of over 167 million people, accounted for 12\% of the world's under-five mortality in 2008 (UNICEF, 2010). Adetunji (2002) reported an unstable pace of decline in under-five mortality in the last four decades and stated that it was faster in the 1960s and 1970s than in recent decades. The country was rated to have had a modest decline in the 1990s alongside Madagascar, Mauritania and Lesotho (Ahmad et al. 2000). Later evidence by Garenne and Gakusi (2006) claimed that under-five mortality may have been steady between 1985 and 2003. This unusual trend might have been occasioned by inconsistencies in the base data used for the analyses. The average annual rate of reduction in under-five mortality between 1990 and 2000 was $-0.3 \%$, for which the country was rated as having $0 \%$ probability of achieving MDG 4 (Murray et al. 2007). The situation

I. ${ }^{+}$Corresponding Author: Joshua O. Akinyemi, Department of Epidemiology and Medical Statistics, Faculty of Public Health, College of Medicine, University of Ibadan. Email: odunjoshua@yahoo.com, jakinyemi@cartafrica.org, Mobile:+234-8077677427 
seems to have improved since 2000 given a report which showed that U5M have reduced at an annual rate of about $2.0 \%$ from 177 in 2000 to 157 per 1000 live births in 2010 (Rajaratnam et al. 2010). Empirical data from the Nigeria Demographic and Health Survey (NDHS) showed an absolute increase of $4.5 \%$ in under-five mortality for the period 1990 2003 and 18.4\% reduction from 1990-2008 (National Population Commission [Nigeria], 2004;2009c). At the current pace, Nigeria is far from the benchmark decline rate of $1 \mathrm{I} .0 \%$ per annum (Lykens et al. 2009) required to attain the MDG4 in West and Central Africa.

Previous studies have identified certain sociodemographic, economic and health factors associated with under-five mortality. For instance, mortality levels decline as the mother's education increases (Bicego and Boerma, 1993; Caldwell, 1979; Cleland and Van Ginneken, 1988). Rural residents experienced poorer child survival (Alao and Adegbola, 1985; Fotso, 2006; Sastry, 2004); and women with shorter birth intervals endanger their children's lives (Amouzou and Hill, 2003). A comprehensive summary of such determinants provided by Rutstein (2000) included: fertility behaviour; nutritional status, use of health services by mothers and or children, environmental health conditions and socioeconomic status. Such findings on determinants of child mortality influenced the design of multi-sectoral interventions to improve child health and survival. In order to explain trends in under-five mortality, these variables themselves ought to have changed over time. The 2008 NDHS report and other evidence indicated that U5M levels are changing in Nigeria. However, it is not clear if there have been changes in the factors associated with children's survival. For child health interventions to be efficient there is a need for prioritisation especially in the face of competition for scarce resources. The order of priority must also be evidence-based. Therefore, the aim of this study is to assess the trends in U5M determinants in Nigeria and determine the independent contribution of the determinants to the apparent changes in $\mathrm{U} 5$ mortality risks.

\section{Literature review and theoretical framework}

This study is based on the framework that all socioeconomic variables operate through a limited set of 'proximate' determinants (intermediate variables) that directly influence the risk of disease and the outcome of disease conditions (Lay and Robilliard, 2009; Mosley and Chen, 1984; Victora et al. 1997). These proximate variables could be sub-classified as biodemographic, environmental and health/behavioural factors.

\section{Biodemographic factors}

The bio-demographic factors include multiplicity of births, mother's age at birth, previous birth interval and sex of the child. Mortality is higher among children from multiple births (twins, triplets, etc.), especially during the neonatal period (Kembo and Van Ginneken, 2009; Luke and Brown, 2006; Uthman et al. 2008). Uthman et al. (2008) found that multiple birth children in Nigeria were twice as likely to die in infancy. There is a U-shaped relationship between childhood mortality and mother's age at birth. The relationship between childhood mortality and maternal age at child's birth is similar to that between the former and birth order because maternal age and birth order are usually correlated. Children born after a short interval to the previous birth generally present higher mortality risks (Manda, 1999). Many studies have reported that males have higher mortality rates at all ages of childhood (Hill and Upchurch, 1995; Lavy et al. 1996; Ssewanyana and Younger, 2007). Similar evidence on the effects of biodemographic factors have been provided by Nigerian studies (Adewuyi and Feyisetan, 1988; Ahonsi, 1995; Lawoyin, 2007).

\section{Environmental factors}

The physical environments to which children are exposed have an influence on morbidity and mortality. The significance of potable safe water and sanitation for child survival has been emphasised by several studies (Franz and FitzRoy, 2006; Satterthwaite et al. 1996). The proximate determinants of childhood mortality in Nigeria are closely associated with neighbourhood and household level characteristics (lyun, 2000). lyun (2000) proposed an ecological hypothesis that the exposure of children to environmental risk factors and infections is a function of the environmental setting in which they are raised. Evidence showed that in most developing countries, infant and childhood mortality is higher in rural than urban settings (Bocquier et al. 201I; Macassa et al. 2004). The urban advantage is however partly reduced or reversed whenever socioeconomic and other demographic variables at individual, household and community levels are controlled (Bocquier et al. 20II; Sastry, 2004). Another environment-related factor that has been found to exhibit pronounced variations in child survival is region (geographical location of residence) and ethnicity. Regional differentials have been documented in many African countries including Nigeria (Adetunji, 2002; Ikamari, 1995; Kuate-Defo, 1996; Manda, 1999). Some of the regional differences found in previous studies were claimed to be due to 
differences in climate/weather, household environmental factors, socio-economic and cultural factors (Adebayo and Fahrmeir, 2005; Kandala et al. 2007).

\section{Health/behavioural factors}

The knowledge and use of pre-natal, post-natal and other healthcare services are important behavioural determinants of childhood mortality (Ahonsi, 1995; Caldwell, 1990; Das Gupta, 1990; Hong et al. 2009; Rutstein et al.2009; Rutstein, 2000). Deaths caused by respiratory diseases, diarrhoea, measles, tetanus and pertussis, which account for more than 65 per cent of all deaths of children in developing countries (Black et al. 20I0) could be prevented by the use of antibiotics, immunisation and oral rehydration therapy. In southwest Nigeria, access to and use of modern health services has been found to be positively associated with child survival (Ahonsi, 1995). A study in Cameroun used father's education and religion as proxies for household behaviour (Kuate-Defo and Diallo, 2002). The argument in support of the approach was that in most African countries, men take decisions on fertility, contraception and use of health care services. These decisions which affect the survival of children depend on the father's level of education. Religion influences attitudes, customs and behaviour relating to fertility, health and diseases. Using NDHS 2003 data, Antai and Antai (2008) reported that religious differentials in Nigerian under-five mortality were explained by differences in community usage of hospital delivery services. The differences were further found to be mediated by education, birth order/interval and residence. Caldwell (1990) had earlier postulated that education has a modifying effect on socio-cultural practices. Other health behavioural factors that have been reportedly associated with child survival include contraception, childhood immunisation, breastfeeding, use of bednet, and medical treatment of childhood illnesses. These factors are directly related to provision and utilisation of healthcare services. Investigations on the roles of these variables are best conducted with surveillance/longitudinal data. Routine immunisation against vaccine preventable diseases is a key child survival intervention which has received enormous funding in recent years. A correlational study had investigated the effect of immunisation on child survival in Nigeria at the macro level (Ngowu et al. 2008). The results showed that literacy and healthcare spending rather than immunisation are important factors driving under-five mortality. Use of bednets is one of the strategies for the prevention of childhood malaria which is a leading cause of death in children. Bednet use is one of the factors responsible for mortality decline among children in Ghana (Nakamura et al.
20II) and Rwanda (Hong et al. 2009). A major challenge in investigating behavioural factors is the limited set of behavioural variables collected in the DHS. This is further complicated by the fact that behaviours are usually based on self-reports. Respondents in community surveys such as the DHS might be reporting what they feel is socially desirable rather than their actual practices.

\section{Socio-economic factors}

Mother's education, father's education and economic well-being (wealth) are the commonest socio-economic factors found to be correlated with child survival. The correlation between mother's education and child mortality is well documented for developing countries (Adetunji, 1994; Ayeni, 1985; Cleland and Van Ginneken, 1988; Nannan et al. 2007). Children of illiterate women have a much higher probability of dying at all ages. With an increasing level of literacy, it is expected that maternal education differentials in overall childhood mortality will reduce (Gakidou et al. 20l0). Economic well-being is commonly measured using wealth indices. Economic well-being may have an effect on mortality probabilities only if not all income-correlated behaviours and risks are included in the analytical model (Kembo and Van Ginneken, 2009).

Several studies in Nigeria and other countries have investigated these individual level proximal and distal factors while the roles of contextual and compositional factors have also received attention (Antai, 20I I; Antai and Antai, 2008; Kuate-Defo, 1996; Sastry, 1997). Many of the previous studies on childhood mortality in Nigeria have been based on cross sectional analysis of data from either tertiary or secondary health facilities (Adewuyi and Feyisetan, 1988; Aikhionbare et al. 1989; Ayoola et al. 2005; Bamgboye and Familusi, 1990) or the NDHS. Very few community based studies have been documented in the literature (Akpala, 1993; Ekanem et al. 1994; Lawoyin, 2007). The majority of the facility and community based studies focused on the causes of death among neonates and infants, while those based on surveys were devoted to childhood mortality determinants. Although there is evidence of decline in under-five mortality levels (Rajaratnam et al. 2010), the extent and effects of changes in mortality determinants have received less attention. Most of the factors (especially socio-economic, behavioural and environmental) that could influence child mortality are expected to have changed over time. Therefore, it is important to analyse the changes in childhood mortality determinants so as to assess their relative contributions to the trend in risk of death. This would help to give a clearer picture of the factors that played dominant roles in the trend as 
this is very important for policy and intervention purposes.

\section{Data and methods}

\section{Setting}

Nigeria lies between latitudes $4^{\circ} 16^{\prime}$ and $13^{\circ} 53^{\prime}$ north and longitudes $2^{\circ} 40^{\prime}$ and $14^{\circ} 4 \mathrm{I}^{\prime}$ east in the West African sub-region. It shares borders with Niger in the north, Chad in the northeast, Cameroon in the east, and Benin in the west and in the south by approximately 850 kilometres of Atlantic Ocean, stretching from Badagry in the west to the Rio del Rey in the east (National Population Commission [Nigeria], 2009c). According to the 2006 population and housing census, Nigeria's population was $140,431,790$ with a national growth rate of $3.2 \%$ per annum (National Population Commission [Nigeria], 2009a). The country is the most populous in Africa and the sixth largest in the world after China, India, USA, Indonesia and Brazil. Politically, Nigeria is made up of 36 states, a Federal Capital Territory and grouped into six geo-political zones (also referred to as regions) namely: North West, North East, North Central, South East, South West and South South. The level of urbanisation is about $45 \%$, but is growing at an estimated rate of $5.3 \%$ per year. It has one of the world's highest urbanisation growth rates (Library of Congress, 2008). Fertility has remained high with a Total Fertility Rate (TFR) of 5.7 since 2003. Life expectancy at birth was put at 51.9 years while the Human Development Index $\mathrm{HDI})$ is 0.459 - ranking 157 out of 187 countries (United Nations Development Programme, 20I I).

\section{Data source}

This study involved a re-analysis of repeated cross sectional nationally representative sample data collected during the Nigerian Demographic and Health Surveys (NDHS) of 1990, 1999, 2003 and 2008. Data collected are highly comparable over time due to uniform standardisation in sampling, data collection methodologies and protocols.

All the surveys were based on a stratified twostage cluster design. Census Enumeration Areas (EAs) which are the primary sampling units were stratified into rural and urban. EAs were then selected in each state by systematic sampling. Subsequently, households were systematically sampled after a listing of all households in the selected EAs. All eligible women (aged 15-49 years) in selected households were interviewed.

Concerning reproduction, women were asked questions about their summary (total children ever born and surviving) and detailed reproductive history, which includes the following: sex and date of every live birth, survival status at time of interview, current age of surviving children and age at death (dead children). The data on age at death were collected in days for children dead within a month of birth, in months for children dead after the first month but before the second birthday and in completed years for deaths occurring at or after the second birthday. Detailed documentation on the sample design and data collection for the surveys are contained in the respective reports (Federal Office of Statistics, 1992; National Population Commission [Nigeria], 2000;2004;2009b). The NDHS recode files for children (births in the last five years before the survey) were analysed.

\section{Ethical considerations}

Formal approval to use the data was obtained from ORC Macro International, the agency responsible for the worldwide Demographic and Health Surveys. The latest in the series of the NDHS (2008) was approved by the National Health Research Ethics Committee, (assigned number NHREC/0I/0I/2007), The committee was yet to be constituted when the earlier surveys were conducted but approval was obtained from relevant government agencies. Informed consent was obtained from the respondents during data collection. The retrieved NDHS data was in anonymous format as identifying information was not collected during the survey. The present study also received formal ethical approval (approved protocol number UI/EC/I2/0I60) from the Institutional Review Committee of the University of Ibadan/University College Hospital, Ibadan, Nigeria (NHREC/05/0I/2008a).

Variables and definitions

Independent Variables: these are the socio-economic and proximate factors outlined below

- Region of residence: categorised as North East, North West, North Central, South East, South West and South South

- Mother's education: This variable was categorised into four levels as: no education, primary, secondary and higher

- Antenatal care: this refers to whether or not the mother received any form of antenatal care from a healthcare professional during the pregnancy of the specific child. Response is either Yes or No

- Skilled delivery: this indicates whether or not a healthcare professional attended the delivery of the child. Response is either Yes or No

- Tetnanus toxoid injection [Yes/No]: the variable indicate whether or not mother received tetanus toxoid vaccination during the pregnancy of the specific child.

- Childhood vaccination [Yes/No]:

- Possession / use of bed net [Yes/No]: 
- Source of drinking water: this was recoded as improved (piped water, protected wells, piped wells/boreholes, protected spring and rain water) and non-improved (unprotected spring, unprotected well etc)

- Toilet facilities: categorised as improved toilet (flush toilet, ventilated/improved latrine or toilet) and non-improved (bucket, open field, bush etc)

- Residence: this is the location where mother/ children live. It is categorised as rural or urban

- Multiplicity of births: whether the birth was multiple or single

- Child's sex: whether male or female

- Birth interval: this is the length of previous birth interval. It was divided into: less than 24 months; 24-35 months and 36 or more months

- Maternal age at birth: this is the age of the mother at the birth of the child. Three categories were used: < 18 years, 18-35 years and $36+$ years

These variables were selected based on the analytical framework and empirical evidence from previous studies. For instance, maternal education was chosen as a proxy for socio-economic status based on a recent evidence from several multivariate models that maternal education was more important for child survival than household wealth (Fuchs et al. 2010). The importance of the other variables have been emphasised by Mahy (2003) and several other studies earlier reviewed.

\section{Data analysis}

Analyses were done using Stata SE version II.I. Design weights were calculated and used in the analyses to account for the complex sample design of the NDHS. Descriptive statistics were generated to summarise and compare the variables across survey years. Absolute changes in each variable were also computed for three periods; 1990-2003, 1990-2008 and 2003-2008. The 1999 survey was excluded from the analysis of changes because it had been reported to have under-estimated childhood mortality (National Population Commission [Nigeria], 2004). Survival analysis techniques was used to identify the predictors of under-five mortality.

\section{Survival analysis}

Kaplan-Meier survival curves were plotted for under-5 mortality using pooled data from the NDHS. Separate curve were drawn for each survey cohort. Survival analysis techniques using Cox proportional hazards regression was employed to identify independent factors associated with under-five mortality from each survey. It is a semi-parametric model proposed by Cox for the study of survival and generation of multivariate life tables (Cox, 1972). The Cox model is more robust than other parametric proportional hazards model because it is not required to specify the parametric form of the distribution of the baseline hazard (Collet, 1994; Vittinghoff et al. 2004). The Cox model used in this study is of the following form:

$$
h_{i}(t)=h_{0}(t) \exp \left(\beta_{1} x_{1}+\beta_{2} x_{2}+\ldots \ldots \ldots+\beta_{p} x_{p}\right)
$$

Equation 1 was re-parameterized and expressed as:

$$
\log _{e} \frac{h_{i}(t)}{h_{0}(t)}=\left(\beta_{1} x_{1}+\beta_{2} x_{2}+\ldots \ldots \ldots+\beta_{p} x_{p}\right)
$$

Where:

$$
\begin{aligned}
& h_{i}(t)=\text { hazard of death for child } i \text { at time } t \\
& h_{0}(t)=\text { baseline hazard at time } t \text { for } x=0 \text { (i.e. all covariates at their appropriate }
\end{aligned}
$$$$
\text { reference levels) }
$$$$
\beta=\text { the vector of unknown coefficients of the explanatory variables } x_{1}, x_{2} \text {, }
$$

$$
\ldots \ldots x_{p}
$$

The dependent variable was the risk (or hazard) of under-five death (0-59 months). Children known to have died before age 60 months were considered as cases, while those still alive at the time of survey data collection were regarded as right-censored observations. Time $t$ was measured as age in months from birth to either death (event of interest) or at time of survey data collection. Children born in the month of data collection were excluded from the analyses because their exposure time to the risk of death would have been zero months. In equation 2 , it was assumed that the hazard ratio does not vary with 
time, giving rise to the proportional hazard assumption for the model. The NDHS data were collected via a stratified multistage sampling procedure in which households were sampled from selected clusters. Clustering results in correlated variables which if used in a regression model can cause a bias for the standard error of estimated parameters and subsequently the inference. In order to reduce this problem, robust standard errors which adjust for clustering were estimated during the model fitting procedures.
Firstly, a pooled model (using merged data for all survey years) was fitted with a dummy variable for survey year. This helped to test whether the hazard rate has changed over time, that is, whether there has been a change in the risk of under-five death over the survey years. This was followed by univariate models to examine the effects of each covariate. Subsequently, a full model with covariates was fitted to assess how the variables influenced the hazards of death in the presence of other covariates.

Table I Description of the Nigeria Demographic and Health Surveys and Kaplan-Meier estimate of childhood mortality rates

\begin{tabular}{llll}
\hline & 1990 & 2003 & 2008 \\
\hline Number of households interviewed & 8999 & 7225 & 34070 \\
\hline No of women I5-49 years interviewed & 878 I & 7620 & 33385 \\
\hline No of under-5 children & & & \\
\hline No of under-5 deaths (\%) & 7819 & 3482 & 28372 \\
\hline KM Mortality rate - I mth & $1035(13.2)$ & $843(14.1)$ & $3185(\mathrm{II} .2)$ \\
\hline KM Mortality rate - II mths & 0.0413 & 0.0496 & 0.0389 \\
\hline KM Mortality rate - 59 mths & 0.0804 & 0.0957 & 0.0729 \\
\hline Hazard ratio & 0.1732 & 0.1813 & 0.1438 \\
\hline
\end{tabular}

Source: Analysis of Nigeria Demographic and Health Survey data for 1990, 2003 and 2008

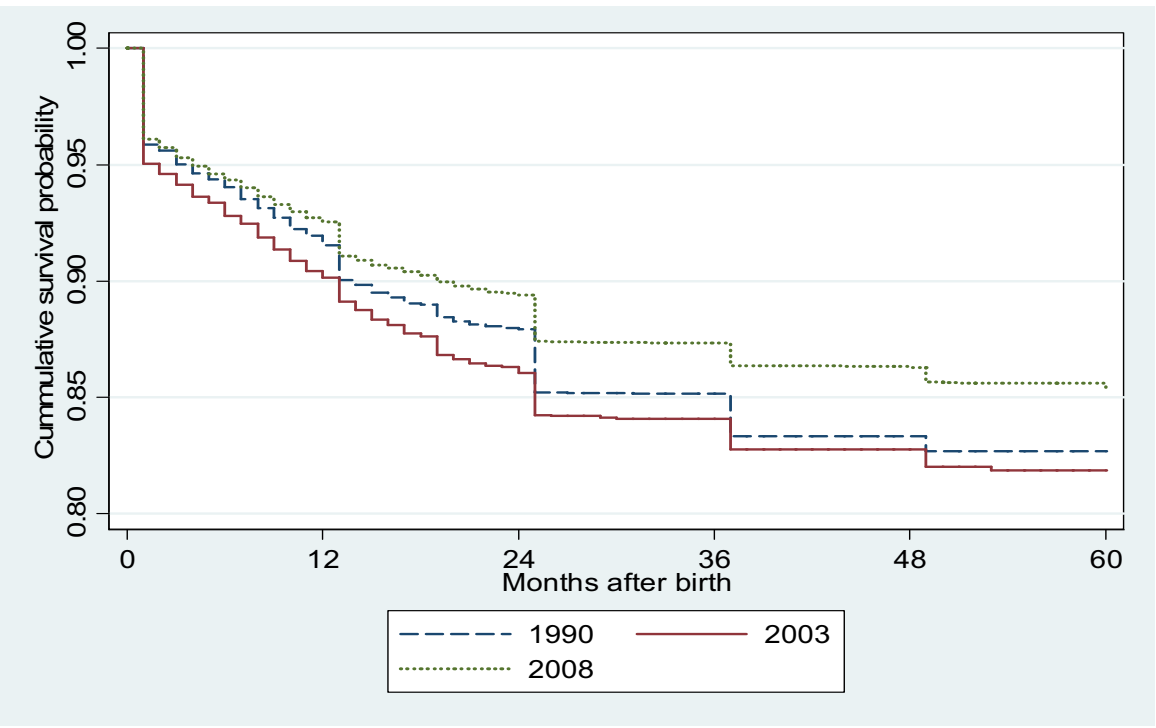

Fig 1. Kaplan-Meier survival curve for under-five children in Nigeria, 1990 - 
Table 2 Trends in factors associated with childhood mortality, Nigeria, 1990 - 2008

\begin{tabular}{|c|c|c|c|c|c|c|}
\hline \multirow[t]{2}{*}{ Factors } & \multicolumn{3}{|c|}{ Percentage } & \multicolumn{3}{|c|}{ Absolute Change } \\
\hline & 1990 & 2003 & 2008 & 1990 & $\begin{array}{l}1990- \\
2008\end{array}$ & $\begin{array}{l}2003- \\
2008\end{array}$ \\
\hline \multicolumn{7}{|l|}{ Socio-economic } \\
\hline maternal education: primary & 26.3 & 24.4 & 22.9 & -1.9 & -3.4 & -1.5 \\
\hline secondary & 13.5 & 21.7 & 22.1 & 8.2 & 8.6 & 0.4 \\
\hline higher & 1.5 & 3.6 & 4.7 & 2.1 & 3.2 & I.I \\
\hline paternal education: primary & 28.5 & 24.3 & 21.3 & -4.2 & -7.2 & -3.0 \\
\hline secondary & 16.8 & 23.8 & 26.2 & 7.0 & 9.4 & 2.4 \\
\hline higher & 5.0 & 11.4 & 10.7 & 6.4 & 5.7 & -0.7 \\
\hline \multicolumn{7}{|l|}{ Behavioural/ health related } \\
\hline antenatal care & 59.4 & 61.9 & 54.9 & 2.5 & -4.5 & -7.0 \\
\hline skilled delivery & 38.3 & 37.8 & 35.3 & -0.5 & -3.0 & -2.5 \\
\hline contraceptive (ever) use & 18.4 & 32.4 & 25.6 & 14.0 & 7.2 & -6.8 \\
\hline tetanus toxoid injection & 55.4 & 55.3 & 52.4 & -0.1 & -3.0 & -2.9 \\
\hline childhood vaccination & 45.7 & 69.9 & 63.4 & 24.2 & 17.7 & -6.5 \\
\hline oral rehydration therapy (ORT) & 11.5 & 19.0 & 25.4 & 7.5 & 13.9 & 6.4 \\
\hline use of bednet & - & 5.7 & 12.8 & & - & 7.1 \\
\hline $\begin{array}{l}\text { medical treatment of childhood } \\
\text { illnesses }\end{array}$ & 67.7 & 65.1 & 85.2 & -2.6 & 17.5 & 20.1 \\
\hline \multicolumn{7}{|l|}{ Environmental } \\
\hline improved source of drinking water & 73.3 & 30.9 & 49.1 & -42.4 & -24.2 & 18.2 \\
\hline improved toilet facilities & 72.2 & 71.2 & 63.2 & -1.0 & -9.0 & -8.0 \\
\hline location : rural & 65.0 & 64.8 & 73.4 & -0.2 & 8.4 & 8.6 \\
\hline : urban & 35.0 & 35.2 & 26.6 & 0.2 & -8.4 & -8.6 \\
\hline \multicolumn{7}{|l|}{ Bio-demographic } \\
\hline no of births : singleton & 96.6 & 95.9 & 96.6 & -0.7 & 0.0 & 0.7 \\
\hline : multiple & 3.4 & 4.1 & 3.4 & 0.7 & 0.0 & -0.7 \\
\hline child's sex : male & 50.4 & 50.8 & 50.9 & 0.4 & 0.5 & 0.1 \\
\hline : female & 49.6 & 49.2 & 49.1 & -0.4 & -0.5 & -0.1 \\
\hline birth order : I & 17.6 & 20.0 & 18.7 & 2.4 & I.I & -1.3 \\
\hline$: 2-3$ & 31.3 & 31.1 & 32.6 & -0.2 & 1.3 & 1.5 \\
\hline$: 4-6$ & 33.3 & 29.9 & 31.4 & -3.4 & -1.9 & 1.5 \\
\hline$: 7+$ & 17.7 & 19.0 & 17.3 & 1.3 & -0.4 & -1.7 \\
\hline birth interval: first birth & 17.7 & 20.0 & 18.7 & 2.3 & 1.0 & -1.3 \\
\hline$:<24$ months & 25.6 & 21.5 & 21.7 & -4.1 & -3.9 & 0.2 \\
\hline$: 24-35$ months & 28.3 & 28.5 & 28.5 & 0.2 & 0.2 & 0.0 \\
\hline$:>=36$ months & 28.5 & 30.0 & 31.1 & 1.5 & 2.6 & 1.1 \\
\hline maternal age : $<20$ years & 6.3 & 6.6 & 5.9 & 0.3 & -0.4 & -0.7 \\
\hline$: 20$ - 35 years & 78.7 & 77.2 & 77.2 & -1.5 & -1.5 & 0.0 \\
\hline$: 36+$ years & 15.0 & 16.3 & 16.9 & 1.3 & 1.9 & 0.6 \\
\hline
\end{tabular}

Source: Analysis of Nigeria Demographic and Health Survey data for 1990, 2003 and 2008

An important component of the analyses is the determination of the contribution of changes in determinants to childhood mortality risk. A factor's relative contribution to the changes in mortality hazard (risk) is both a function of its estimated coefficient and the degree of change in its actual value over time. Thus a quantitatively large and statistically significant association of a covariate with mortality can only induce an actual change in the overall mortality risk if the level of that covariate changed over time (perhaps due to some interventions). The relative contributions of each of the covariates in the 
model were obtained for 1990-2003, 1990-2008 and 2003-2008. Firstly, the Cox hazard regression analysis was carried out to determine the regression coeffcients from the 1990 and 2003 NDHS data. Secondly, changes in the covariates between survey years were calculated (for 1990-2003, 1990-2008 and 2003-2008). Thirdly, changes in covariates were multiplied by the regression coefficient (i.e changes from 1990-2003 and 1990-2008 were multiplied by
1990 coefficient while changes from 2003-2008 were multiplied by 2003 coefficient). The exponential of the resulting value minus I gives the proportional change in the hazard rate due to the change in that factor. Lastly, the products of the changes in covariates and their regression coefficients were summed together and then exponentiated to get the change in mortality due to changes in all the covariates between two consecutive surveys.

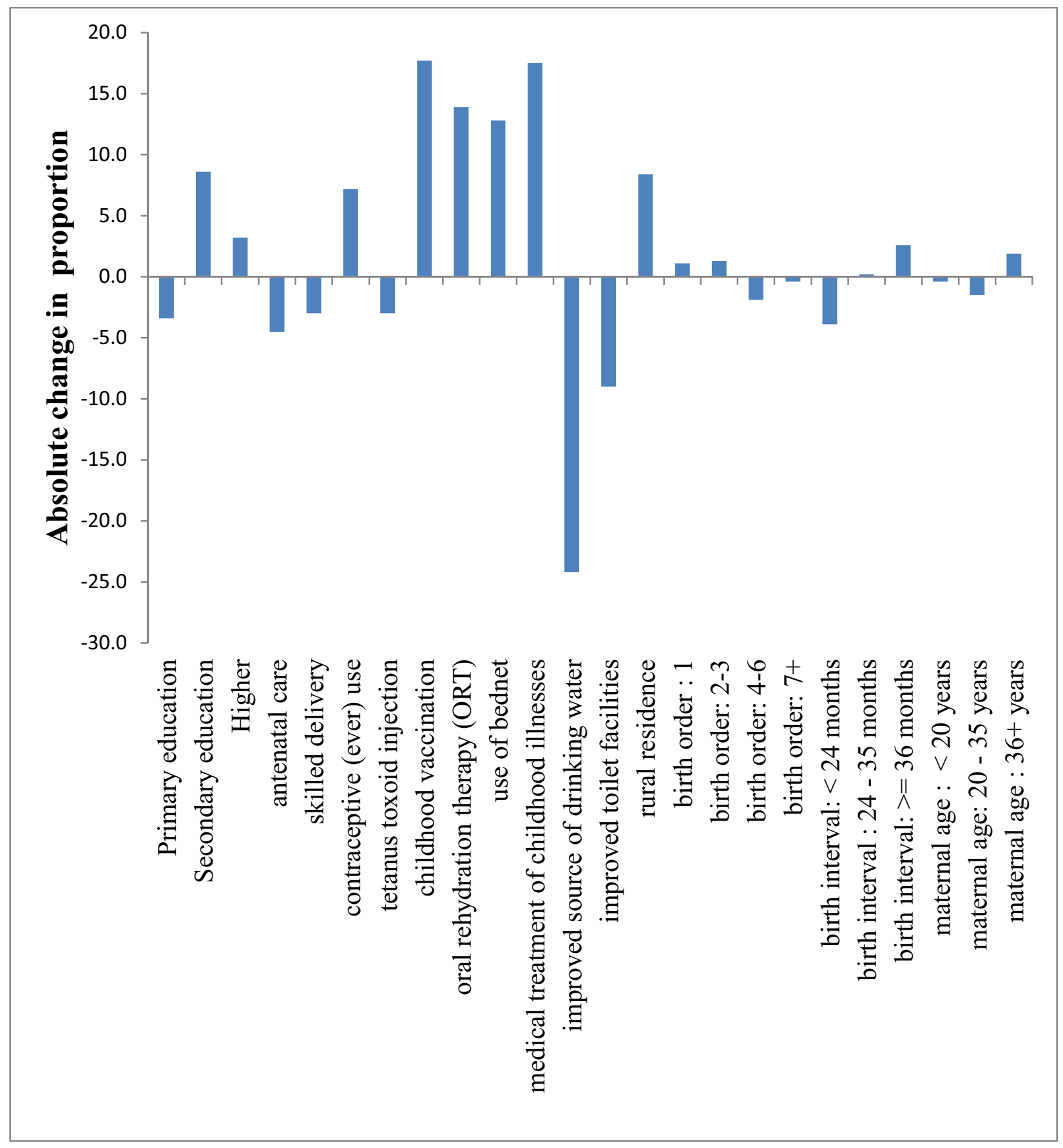

Fig 2: Absolute changes in selected factors associated with under-five mortality in Nigeria, 1990 - 2008 
Table 3 Effects of selected factors associated with under-5 mortality, Nigeria 1990-2008

\begin{tabular}{|c|c|c|}
\hline & Univariate models & Full model \\
\hline Factors & HR (95\% Cl) & HR (95\% Cl) \\
\hline \multicolumn{3}{|l|}{ Region } \\
\hline North West & $\mathrm{I} .07(0.93-\mathrm{I} .24)$ & $1.25(0.81-1.96)$ \\
\hline North East & $1.39(1.23-1.57)^{*}$ & $1.47(0.90-2.39)$ \\
\hline North Central & $1.46(1.29-1.65)^{*}$ & $1.24(0.81-1.91)$ \\
\hline South East & $\mathrm{I} .05(0.89-\mathrm{I} .24)$ & $1.23(0.7 \mathrm{I}-2.13)$ \\
\hline South South & $0.75(0.62-0.91)^{*}$ & $0.97(0.58-1.62)$ \\
\hline South West (ref) & 1.00 & 1.00 \\
\hline
\end{tabular}

\section{Socio-economic}

\begin{tabular}{clll}
\hline maternal education: & primary & $0.8 \mathrm{I}(0.74-0.88)^{*}$ & $\mathrm{I} .25(0.95-\mathrm{I} .64)$ \\
\hline secondary & $0.6 \mathrm{I}(0.55-0.68)^{*}$ & $0.96(0.65-\mathrm{I} .4 \mathrm{I})$ \\
\hline higher & $0.34(0.26-0.46)^{*}$ & $0.5 \mathrm{I}(0.19-\mathrm{I} .33)$
\end{tabular}

\begin{tabular}{|c|c|c|}
\hline \multicolumn{3}{|l|}{ Behavioural and health related } \\
\hline antenatal care & $0.66(0.60-0.73)^{*}$ & $0.8 \mathrm{I}(0.59-\mathrm{I} . \mathrm{I} 3)$ \\
\hline skilled delivery & $0.68(0.62-0.74)^{*}$ & $1.16(0.81-1.66)$ \\
\hline tetanus toxoid injection & $0.65(0.58-0.7 \mathrm{I})^{*}$ & $0.76(0.42-1.39)$ \\
\hline child immunisation & $0.56(0.5 \mathrm{I}-0.60)^{*}$ & $0.90(0.67-1.23)$ \\
\hline use of bednet & $0.99(0.87-1.14)$ & $0.86(0.63-1.17)$ \\
\hline \multicolumn{3}{|l|}{ Environmental } \\
\hline improved source of drinking water & $0.76(0.7 \mathrm{I}-0.8 \mathrm{I})^{*}$ & $\mathrm{I} .09(0.86-\mathrm{I} .39)$ \\
\hline improved toilet facilities & $0.97(0.90-1.06)$ & $0.94(0.75-1.17)$ \\
\hline urban residence & $0.64(0.58-0.70)^{*}$ & $0.77(0.57-1.03)$ \\
\hline \multicolumn{3}{|l|}{ Bio-demographic } \\
\hline Multiple birth & $2.87(2.52-3.27)^{*}$ & $6.64(4.68-9.42)^{*}$ \\
\hline child's sex : male & $1.15(1.08-1.28)^{*}$ & $1.09(0.88-1.35)$ \\
\hline birth interval: $<24$ months & $2.08(1.89-2.28)^{*}$ & $3.38(2.5 \mathrm{I}-4.56)^{*}$ \\
\hline$: 24-36$ months & $\mathrm{I} .39(\mathrm{I} .27-\mathrm{I} .5 \mathrm{I})^{*}$ & $2.13(\mathrm{I} .6 \mathrm{I}-2.82)^{*}$ \\
\hline$:>=36$ months (ref) & 1.00 & 1.00 \\
\hline maternal age $:<18$ years & $1.45(\mathrm{I} .27-\mathrm{I} .65)^{*}$ & $0.80(0.36-1.77)$ \\
\hline : 18 - 34 years (ref) & 1.00 & 1.00 \\
\hline$: 36+$ years & $1.20(1.10-1.3 \mathrm{I})^{*}$ & $0.99(0.77-1.26)$ \\
\hline
\end{tabular}

* $\mathrm{p}<0.05$ (statistically significant)

Source: Analysis of Nigeria Demographic and Health Survey data for 1990, 2003 and 2008

\section{Results}

A total of 7189,3482 , and 28372 under-5 children from 1990, 2003 and 2008 NDHS respectively were included in the analyses (Table I). Of these numbers, there were 1035 (13.2\%), 843 (14.1\%) and 3185
(11.2\%) under-five deaths in 1990, 2003 and 2008 respectively. A Kaplan-Meier estimate of mortality showed that at 59 months of life the childhood mortality rate increased from 173.2 per 1000 in 1990 to 181.3 per 1000 in 2003 but reduced to 143.8 per http://aps.journals.ac.za/ 
1000 in 2008. The survival pattern over the years is clearly illustrated by the survival curve in Figure I which shows that the pattern is the same for NDHS 1990, 2003 and 2008. However, there were steep drops (indicating heavy mortality) at very young ages till about 24 months, after which there were fewer deaths. Figure I also confirmed that under-5 deaths increased between 1990 and 2003 but later reduced, between 2003 and 2008. The survival pattern before age 12 months was similar in 1990 and 2008. After 12 months, the gap in the survival curve for 1990 and 2008 became widened. This implied that there were greater reductions in mortality during age $\mathrm{I}-4$ years than during infancy ( $0-1 \mathrm{I}$ months).

\section{Trends in determinants of under-five mortality}

Table 2 showed the trends and absolute changes in some of the factors known to be associated with under-five mortality. The proportion of mothers with secondary education increased from $13.5 \%$ in 1990 to about $21.7 \%$ in 2003, which it barely maintained 5 years later in 2008 (22. 1\%). The few behavioural or health related factors that maintained a sort of increase from 2003 were the use of oral rehydration therapy $(25 \%)$ and medical treatment of childhood illnesses (85\%). Other factors including antenatal clinic attendance, use of contraceptives, childhood vaccination and skilled delivery declined from their figures in 2003. There were very slow but gradual reductions over the period 1990 to 2008 in the proportion of children with prior birth interval below 24 months (3.9\%), antenatal clinic attendance (4.5\%), skilled delivery $(3.0 \%)$ and availability of improved source of drinking water (24.2\%). Use of treated bed nets increased from about $6 \%$ in 2003 to $13 \%$ in 2008. Biodemographic factors such as birth interval and maternal age appeared fairly stable over the 19 years period as shown in Figure 2. Over these periods, there was a reduction in the proportion of mothers with primary education, antenatal care, skilled attendance at delivery, improved source of drinking water and sanitation facilities. The proportion of children with birth intervals less than 24 months also reduced.

\section{Effects of selected determinants on under-five mortality risks}

Table 3 summarises the hazard ratios from univariate and full models for factors associated with child survival. These hazard ratios were obtained from the pooled data for 1990, 2003 and 2008. Thus, they represent the average effect of the variables over the study period. The univariate models showed that virtually all variables influenced child survival in
Nigeria in the expected direction. The risk of under5 death is higher in the Northern than the Southern regions of Nigeria. Children of mothers with secondary or higher education have greater survival chances than those born to women without formal education. Behavioural and health-related factors such as antenatal care, skilled attendant at delivery, immunisation all enhanced children survival. Multiplicity of births and shorter birth intervals were found to be risk factors for under-five mortality.

The full multivariate model provide the average effect of each covariate while controlling for the effects of other variables in the model. This model revealed that multiplicity of birth and birth interval are important predictors of under-five mortality in Nigeria.

The multivariate model described in Table 3 above was stratified by year of survey in order to understand how the effects of the covariates on child survival have changed over time. Table 4 revealed that regional differences (across geopolitical zones in Nigeria) in under-five mortality risks were not statistically significant when other potential determinants were included in the Cox hazard model. Furthermore, the results for 1990 showed that children whose mothers had secondary $(\mathrm{HR}=0.85, \mathrm{Cl}=0.55-\mathrm{l} .33)$ or higher $(\mathrm{HR}=0.47$, $\mathrm{Cl}=0.15-\mathrm{I} .45)$ education had lower risks of underfive deaths than those whose mothers had no formal education. Also, tetanus toxoid injection by mothers during pregnancy $(\mathrm{HR}=0.82, \mathrm{Cl}=0.64-\mathrm{I} .05)$, access to improved sources of drinking water $(H R=0.76$, $\mathrm{Cl}=0.59-0.99)$ and use of improved toilet facilities $(\mathrm{HR}=0.83, \mathrm{Cl}=0.67-\mathrm{I} .03)$ were associated with a reduced risk of under-five death for the 1990 cohort. The risk of under-five death was three times higher for multiple birth children $(H R=3.0 \mathrm{I}$, $\mathrm{Cl}=2.14$-4.22). Other risk factors include male gen$\operatorname{der}(\mathrm{HR}=\mathrm{I} .20, \mathrm{Cl}=\mathrm{I} .0 \mathrm{I}-\mathrm{I} .43)$ and birth interval less than 24 months $(\mathrm{HR}=1.78, \mathrm{Cl}=1.39-2.28)$ and young maternal age at birth $(\mathrm{HR}=1.24, \mathrm{Cl}=0.79$ 1.94). In the NDHS 2003 cohort, only multiplicity of births and shorter birth intervals had statistically significant independent effects on under-five death. The hazard of death below age five was about 8 times higher among multiple birth children $(\mathrm{HR}=7.89, \mathrm{Cl}=5.49-\mathrm{I} \mid .35)$. Variables such as secondary education $(\mathrm{HR}=0.55, \mathrm{Cl}=0.20-\mathrm{I} .50)$, higher education $(\mathrm{HR}=0.27, \mathrm{Cl}=0.03-2.32)$, antenatal care $(\mathrm{HR}=0.76, \mathrm{Cl}=0.43-\mathrm{I} .35)$, tetanus toxoid injection $(\mathrm{HR}=0.76, \mathrm{Cl}=0.42-\mathrm{I} .39)$ also improved in their protective effects against under-five death compared to the result in the 1990 cohort.

As earlier stated, the purpose of Table 4 is to highlight the changes in the effects of the factors analysed during the 19 year period covered by the 
study. It was observed that the hazard of death for North-East and North-West relative to South-West increased between 1990 and 2003 while it reduced between 2003 and 2008. The results also showed that the hazard ratios for primary, secondary and higher maternal education increased between 1990 and 2008, which means that the survival advtantage conveyed by maternal education reduced over the years when other variables were controlled. Antenatal care (1990: HR=0.96 (0.74-I.25); 2008: $H R=0.83(0.62-I .10))$. and use of bednet (2003: $\mathrm{HR}=\mathrm{I} .16$ (0.43-3. I0)); 2008: HR=0.83 (0.59-I.I5)) increased in their protective effect against under-five deaths.

Table 4 Trends in effects of selected factors associated with under-5 mortality, Nigeria 1990-2008

\begin{tabular}{llll}
\hline & $\mathbf{1 9 9 0}$ & $\mathbf{2 0 0 3}$ & $\mathbf{2 0 0 8}$ \\
\hline Ractors & HR (95\% CI) & HR (95\% CI) & HR (95\% CI) \\
\hline Negion & & & \\
\hline North West & $\mathrm{I} .16(0.77-\mathrm{I} .75)$ & $\mathrm{I} .47(0.43-5.10)$ & $\mathrm{I} . \mathrm{I5}(0.73-\mathrm{I} .82)$ \\
\hline North Central & $0.96(0.66-\mathrm{I} .40)$ & $2.78(0.72-\mathrm{I0.8})$ & $\mathrm{I} .15(0.72-\mathrm{I} .83)$ \\
\hline South East & $\mathrm{NA}$ & $\mathrm{I} .50(0.47-4.83)$ & $\mathrm{I} .16(0.73-\mathrm{I} .83)$ \\
\hline South South & $0.77(0.55-\mathrm{I} .09)$ & $0.74(0.16-3.44)$ & $\mathrm{I} .20(0.67-2.15)$ \\
\hline South West (ref) & $\mathrm{NA}$ & $\mathrm{I} .52(0.45-5.12)$ & $0.85(0.48-\mathrm{I} .49)$ \\
\hline
\end{tabular}

Socio-economic

\begin{tabular}{|c|c|c|c|}
\hline maternal education: primary & $\mathrm{I} .08(0.8 \mathrm{I}-\mathrm{I} .44)$ & $\mathrm{I} .34(0.8 \mathrm{I}-2.20)$ & $1.22(0.89-1.67)$ \\
\hline secondary & $0.85(0.55-1.33)$ & $0.55(0.20-1.50)$ & $\mathrm{I} . \mathrm{II}(0.75-\mathrm{I} .66)$ \\
\hline higher & $0.47(0.15-1.45)$ & $0.27(0.03-2.32)$ & $0.60(0.21-1.69)$ \\
\hline
\end{tabular}

\section{Behavioural and health related}

\begin{tabular}{llll}
\hline antenatal care & $0.96(0.74-\mathrm{I} .25)$ & $0.76(0.43-\mathrm{I} .35)$ & $0.83(0.56-\mathrm{I} .23)$ \\
\hline skilled delivery & $\mathrm{I} .0 \mathrm{I}(0.74-\mathrm{I} .39)$ & $\mathrm{I} .32(0.53-3.29)$ & $\mathrm{I} .17(0.82-\mathrm{I} .66)$ \\
\hline tetanus toxoid injection & $0.82(0.64-\mathrm{I} .05)$ & $0.76(0.42-\mathrm{I} .39)$ & $0.9 \mathrm{I}(0.64-\mathrm{I} .30)$ \\
\hline child immunisation & $0.72(0.60-0.86)^{*}$ & $0.9 \mathrm{I}(0.54-\mathrm{I} .52)$ & $\mathrm{I} .09(0.85-\mathrm{I} .40)$ \\
\hline use of bednet & $\mathrm{NA}$ & $\mathrm{I} .16(0.43-3.10)$ & $0.83(0.59-\mathrm{I} .15)$
\end{tabular}

\section{Environmental}

\begin{tabular}{llll}
\hline improved source of drinking water & $0.76(0.58-0.99)^{*}$ & $\mathrm{I} .53(0.75-3.14)$ & $\mathrm{I} .05(0.8 \mathrm{I}-\mathrm{I} .35)$ \\
\hline improved toilet facilities & $0.83(0.67-\mathrm{I} .03)$ & $0.75(0.43-\mathrm{I} .30)$ & $0.96(0.76-\mathrm{I} .23)$ \\
\hline urban residence & $\mathrm{I} .04(0.78-\mathrm{I} .39)$ & $0.68(0.29-\mathrm{I} .56)$ & $0.83(0.59-\mathrm{I} . \mathrm{I})$
\end{tabular}

\section{Bio-demographic}

\begin{tabular}{|c|c|c|c|}
\hline Twin birth & $3.01(2.14-4.22)^{*}$ & $3.08(1.11-8.56)^{*}$ & $7.89(5.49-11.35)^{*}$ \\
\hline child's sex : male & $\mathrm{I} .20(\mathrm{I} .0 \mathrm{I}-\mathrm{I} .43)^{*}$ & $0.91(0.55-1.49)$ & $1.13(0.90-1.40)$ \\
\hline birth interval: $<24$ months & $1.78(1.39-2.28)^{*}$ & $3.64(1.68-7.91)^{*}$ & $3.25(2.35-4.49)^{*}$ \\
\hline$: 24$ - 36 months & $1.40(1.13-1.75)^{*}$ & $2.98(1.50-5.93)^{*}$ & $1.90(1.38-2.6 \mathrm{I})^{*}$ \\
\hline$:>=36$ months (ref) & 1.00 & 1.00 & 1.00 \\
\hline maternal age $:<18$ years & $1.24(0.79-1.94)$ & $0.33(0.05-2.15)$ & $0.97(0.41-2.30)$ \\
\hline$: 18$ - 34 years (ref) & 1.00 & 1.00 & 1.00 \\
\hline$: 36+$ years & $1.22(0.96-1.54)$ & $1.21(0.69-2.14)$ & $0.94(0.72-1.23)$ \\
\hline
\end{tabular}

NA-Data not available; * $\mathrm{p}<0.05$ (statistically significant)

Source: Analysis of Nigeria Demographic and Health Survey data for 1990, 2003 and 2008 
Childhood immunisation which was significant in 1990 was no longer a significant protective factor in 2003 and 2008. The urban survival advantage was increased between $1990(\mathrm{HR}=\mathrm{I} .04(0.78-\mathrm{I} .39))$ and $2003(\mathrm{HR}=0.68(0.29-\mathrm{I} .56))$ but was reduced between 2003 and $2008(\mathrm{HR}=0.83(0.59-\mathrm{I} . \mathrm{I5}))$. For bio-demographic variables, while the risk associated with multiplicity of births and shorter birth intervals increased over time, young maternal ages (less than 18 years) became less risky.

\section{Relative contribution of changes in determinants to under-five mortality risk}

The relative contribution of the changes in factors to under-five mortality risk are shown in Table 5 . Between 1990 and 2003, increase in maternal education, antenatal care, childhood vaccination and birth interval resulted in a reduction in mortality risk. This slight reduction was, however, largely offset by poorer access to improved source of drinking water and toilet facilities which resulted in $18.72 \%$ and $0.15 \%$ increase in risk of under-five death respectively. Increase in multiple births also played a role in increasing the risk of under-five death by $0.82 \%$. The contributions of factors to changes between 1990 and 2008 was similar to those observed for 1990-2003 but with slightly different magnitudes. For instance, increase in the proportion of mothers with a higher educational qualification translated into $2.40 \%$ reduction in risk between 1990-2008 compared to $1.58 \%$ in 1990-2003. Reduction in access to an improved source of drinking water resulted in about $10 \%$ rise in risk of childhood death. A decrease in proportion of births below 24 months caused a $2.17 \%$ fall in mortality risk. The fall in under-five mortality risk between 2003 and 2008 could have been aided by a slight improvement in antenatal care (1.78\%), access to an improved source of drinking water $(7.09 \%)$ increased urbanisation $(3.39 \%)$ and availability of improved toilet facilities in the household (1.86\%). The results showed that changes in the variables increased the death hazards by $4.6 \%$ between 1990-2003, while the risk reduced by merely $2 \%$ from 1990-2008. During the period 2003-2008, changes in the variables caused under-five mortality risk to be reduced by $12.0 \%$

\section{Discussion}

The purpose of this study was to determine changes in Nigeria childhood mortality determinants and their effects on child survival. Repeated cross sectional data on under-five children in the Nigerian Demographic and Health Surveys (1990, 2003 and 2008) have been re-analysed to explore the dynamics of under-five survival. Kaplan-Meier estimates of survival probabilities showed that under-five mortality increased between 1990 and 2003 while there was a reduction from 2003 to 2008 . Overall, the risk of under-five deaths reduced between 1990 and 2008. The age pattern of childhood mortality as illustrated by the survival curve showed that greater reduction was recorded from 12 months onward while mortality was very high in infancy. This observed pattern is well established in the literature which has indicated that when childhood mortality is declining, it is more noticeable from ages I-4 years than during infancy (Bicego and Ahmad, 1993). The heavier mortality in early life seems not to have changed much over the years. Beyond infancy, some improvements have been recorded in Nigerian child survival.

This study has shown that many of the determinants of under-five mortality in Nigeria had varying degrees and directions of change between 1990 and 2008. The improvement in the levels of maternal and paternal education observed was not unexpected given the renewed improvement in the provision of formal education and literacy rate in the country (Worldbank, 2012). All the tiers of government in Nigeria have also made several efforts at increasing the proportion of the population with formal education. The introduction of universal basic education, one of the MDGs and targeted at free and compulsory basic education, is an example of such initiatives by the government (UBEC, 20I2). Increased educational attainment is not only a Nigerian phenomenon but a global one whose effect on childhood mortality reduction has been previously reported (Gakidou et al. 20 I0; Nannan et al. 2007). The findings that very little changes were recorded for variables related to maternal health such as antenatal care, skilled delivery, contraceptive use and tetanus toxoid injection during pregnancy between 1990 and 2008 were worrisome. This could be a result of population expansion without an attendant increase in coverage of healthcare services. The number of health facilities and personnel have remained virtually the same for almost two decades, whereas there has been a surge in population size. Childhood vaccination and use of oral rehydration therapy improved slightly, probably because of immunisation campaigns mounted by government and other development partners such as $\mathrm{WHO}$ and UNICEF. The coverage is, however, still far from optimum level. The slight improvement also recorded for medical treatment of childhood illnesses such as diarrhoea, cough, pneumonia and malaria may have been the effect of external support from different agencies (Lykens et al., 2009). 


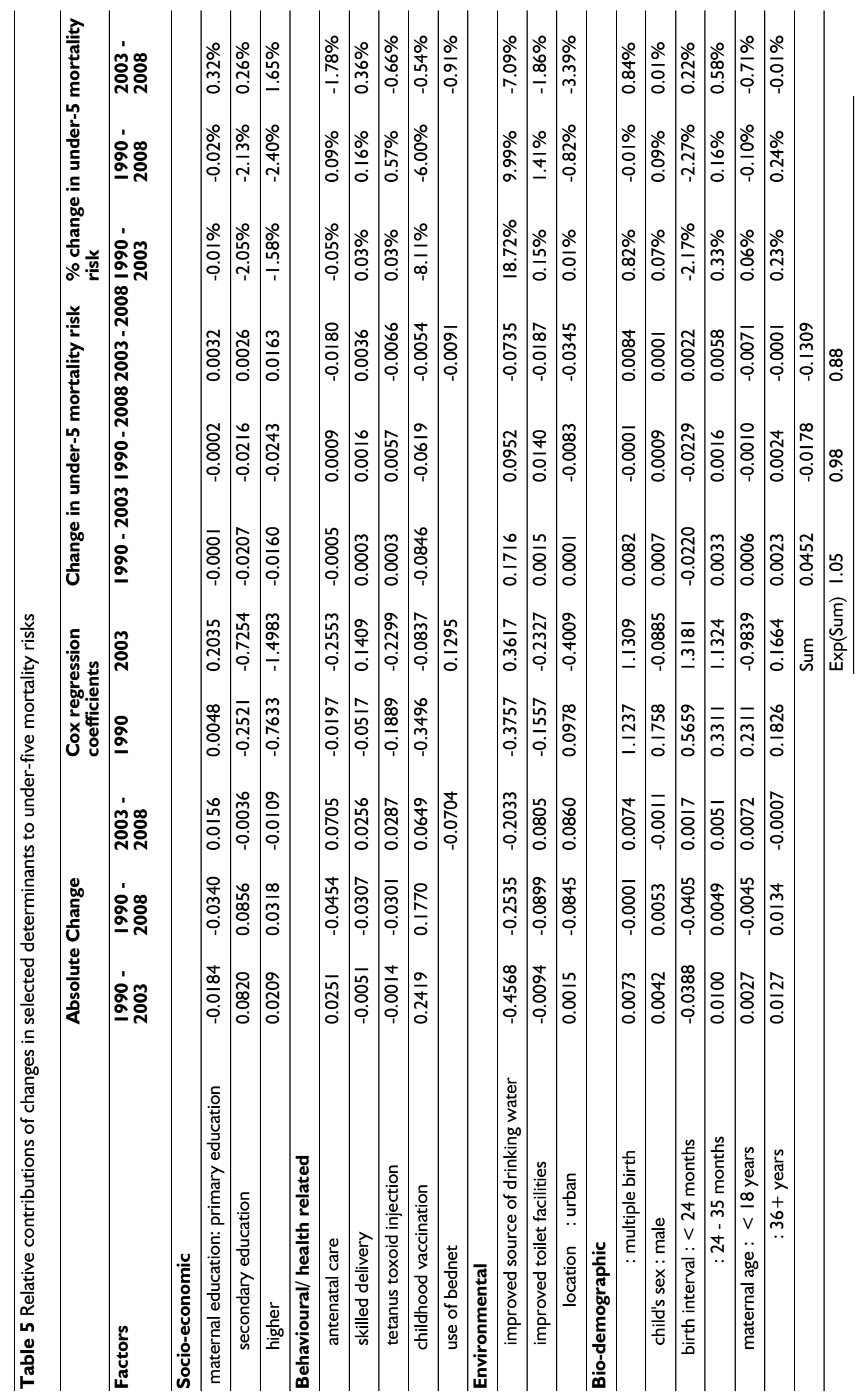


Poor access to potable drinking water could partly explain the high under-five mortality in Nigeria as evidence has shown that the source of drinking water has a direct link with diarrhoea, which is one of the leading causes of under-five death (Black et al. 2010). Non-availability or poor access to drinking water in Nigeria may probably be one of the impacts of infrastructure decay in the country (Mabogunje, 2007). In the late 1990s, most urban cities in Nigeria had access to pipe-borne water, but this disappeared in recent years due to increased urbanisation and poor maintenance of water infrastructure in most cities. Reduction in access to improved water source was also reported in Ghana between 2003 and 2008 (Nakamura et al. 20I I) and between 2000 and 2005 in Rwanda (Hong et al. 2009). The magnitude of reduction in the two countries was, however, lower than what obtained in Nigeria.

Bio-demographic factors such as birth order, birth interval and maternal age at birth remained virtually unchanged over the years. This is not very surprising, as fertility in Nigeria has remained high in the last 2 decades. These are behavioural issues which cannot be separated from socio-cultural practices and it take a lot of efforts driven by massive improvement in formal education to change these factors (Caldwell, 1990).

The models revealed that many of the covariates affected under-five mortality in the expected directions. The magnitude of the effects, however, varied from one survey to another. Regional disparities were significant between the northern and southern regions in 1990, 2003 and 2008. This is not a new phenomenon as far as child health and survival is concerned in the country. Regional inequalities have been explained in terms of socio-economic and other factors (Adetunji, 2002; Antai, 20I I). Maternal education was found to be inversely related to under-5 mortality. Specifically, higher education promotes child survival. This is also a well established fact in previous studies (Adetunji, 1995; Fuchs et al. 2010; Gakidou et al. 2010) and the mechanism by which this operates have also been suggested (Caldwell, 1979; 1990; Cleland and Van Ginneken, 1988).

Behavioural and health-related factors that focused on maternal/child care practices such as antenatal care, skilled delivery, tetanus toxoid injection during pregnancy, child immunisation and contraception were also found to promote child survival. These practices help with the early detection and management of pregnancy/delivery complications which may threaten the life of mother/child. For instance, tetanus toxoid injections protect the child against neonatal tetanus which is one of the commonest causes of infant deaths. Use of contraception may not have a direct effect on child survival but it enhances birth spacing and longer birth interval which could guarantee better health and development for the child (Manda, 1999; Rutstein, 2005).

The results also confirmed the survival advantage of children in urban settings and those whose households have improved sources of drinking water and sanitation (toilet) facilities. Availability of these basic amenities is one of the main explanations for the urban advantage in child survival (Bocquier et al. 20II). Household environmental factors such as water source, toilet type, cooking fuel, floor type, etc. have been reported to play important roles in child morbidity and mortality (Fayehun, 2010; lyun, 2000). The age-old roles of bio-demographic factors were also emphasised by the results. For instance, multiple births and male children have higher risks of death. Multiplicity of births increases the risk of low birth weight and other complications in the perinatal period (Uthman et al. 2008).

\section{Trends in effects and relative contributions of under-five mortality determinants}

Regional inequalities in the hazard of under-five deaths widened between 1990 and 2003 but narrowed from 2003 to 2008 but was not statistically significant. This agrees with previous hypotheses that regional inequalities in Nigerian child survival is driven largely by socio-economic and other background characteristics (Antai, 2008). The basis of most regional variations is socio-cultural practices which varied across ethnic groups (Brockerhoff and Hewett, 2000). These practices have an over-bearing influence on many of the background characteristics. Consequently, when these background variables are included in regression models along with region, they dampen the effect of regional differences. Similar effects have earlier been reported by Fayehun and Omololu (20II) in a study on ethnicity and child survival in Nigeria. The various geo-political regions in Nigeria are composed of homegeneous ethnic groups.

The risks associated with multiple births and shorter birth intervals increased in 2003 and 2008. This worrisome trend may be due to poor utilisation of maternal/child care services as reported in this study. With a very low contraceptive usage and a high unmet need for family planning in Nigeria, adequate birth spacing would be difficult to achieve. The results also further emphasised the significant influence of multiplicity of births and short birth intervals as risk factors of under-five mortality in Nigeria (Uthman et al. 2008) and other countries (Alam et al. 2007). Multiple birth children are at higher risks of low birth weight and other complications as well 
as prematurity which is also a leading cause of underfive death (Black et al. 20I0). A study in Zimbabwe also found (Kembo and Van Ginneken, 2009) that multiple birth children were more than twice as likely to die during infancy compared to single births. The importance of these bio-demographic factors especially during infancy have been previously highlighted by Omariba et al. (2007).

This study also showed that the effect of changes on mortality risk is proportional to the magnitude of the changes in the determinants. This conforms with previous reports that countries with slight changes in determinants also recorded minimal changes in mortality risk (Rutstein, 2000). The poor improvements in determinants of under-five mortality and the attendant high under-five mortality in Nigeria observed in this study, corroborates the view by Rutstein (2000) that a substantial reduction in underfive mortality risk requires a combination of several factors such as maternal education, antenatal care, childhood vaccination, use of bednets, improvement in household environmetal health and birth spacing. A study in Ghana found increased bednet use, widened birth interval and maternal education as factors responsible for the current improvement in the country's under-five mortality (Nakamura et al. 20II). Similar results were reported in Rwanda (Hong et al. 2009) and Republic of Benin (Rutstein et al. 2009). Some variables like ORT usage and medical treatment of childhood illnesses were not included in the multivariate analyses because data were not available for dead children. The influence of such unmeasured factors have also been recognised in other similar studies (Nakamura et al. 20I I; Nuwaha et al. 20II; Rutstein et al. 2009; Rutstein, 2000).

\section{Limitations and strengths of the study}

Some limitations need to be borne in mind in the interpretation of the findings in this study. Firstly, the analyses were based on cross-sectional data, therefore causal relationships between the factors analysed and childhood mortality could not have been established. Secondly, a small proportion of childhood mortality changes were explained by the factors analysed. This implies that the roles of unmeasured/unobserved factors are quite substantial. Even though NDHS collected data on important child survival interventions such as nutritional status, use of ORT and treatment of childhood illnesses which could explain mortality changes, such data are available for living children only. This selection bias limits the usefulness of these variables in a multivariate analysis.

These limitations notwithstanding, the strengths of this study include the fact that it is based on nationally representative data which could easily be generalised to the entire country. It is the first known attempt at assessing the progress in determinants and effects on childhood mortality in Nigeria.

\section{Conclusion}

Child survival has improved in Nigeria between 1990 and 2008. The country recorded very minimal improvements in bio-demographic and maternal/ child health factors associated with under-five mortality. Household access to improved sources of drinking water, sewage disposal, birth spacing and childcare practices are the important factors driving mortality changes. Efforts aimed at improving child survival interventions and other factors need to be accelerated to move nearer the MDG 4.

The findings in this study have important policy implications. Reduction in under five-mortality could be achieved in Nigeria with a substantial improvement in female education, behavioral/health-related, household environmental health factors and birth practices. Many of these factors are at the centre of the MDG, in which Nigeria is rated as having not made sufficient progress. Birth spacing needs to be widely promoted in the country while quality maternal and child health services should also be made available to curtail the risks associated with multiple births and other complications. In this regard, the ongoing massive recruitment of midwives by the National Primary Health Care Development Agency to boost maternal and child health care services coverage in rural areas is highly commendable and should be sustained.

\section{Acknowledgement}

We sincerely thank the ORC Macro International for permission to use the NDHS data. We also express our appreciation to the National Population Commission, Abuja, Nigeria and other partners involved in the NDHS. Many thanks to an anonymous reviewer whose comments helped to improve the quality of the paper.

This research was [partially] funded by a Fellowship award to the first author (JOA) provided by the Consortium for Advanced Research Training in Africa (CARTA). CARTA has been funded by the Wellcome Trust (UK) (grant:087547/Z/08/Z), the Department for International Development under the Development Partnerships in Higher Education (DelPH E), the Carnegie Corporation of New York (grant: B 8606), the Ford Foundation (grant: II00-0399), and the Bill and Melinda Gates Foundation (grant: 5I228) 


\section{References}

Adebayo, S. B., and Fahrmeir, L. 2005. Analysing child mortality in Nigeria with geoadditive discrete-time survival models. Statistics in Medicine 24.5: 709-728.

Adetunji, J. A. 1994. Infant mortality in Nigeria: effects of place of birth, mother's education and region of residence. Journal of Biosocial Science 26.4: 469-477.

. 1995. Infant mortality and mother's education in Ondo State, Nigeria. Social Science and Medicine 40.2: I 200-I 206. 2002. Levels, Trends and Regional Differentials in the Death rates of Nigerian Children: A Policy and Research Paper. Paper presented at the Annual Meeting of the American Public Health Association, Philadelphia PA.

Adewuyi, A. A., and Feyisetan, B. J. 1988. Correlates of infant mortality: Empirical evidence from lle Ife, Nigeria. IDRC CRDI CIID Manuscript Report 19/e. Ottawa, Canada.

Ahonsi, B. A. 1995. Age variations in the proximate determinants of child mortality in south-west Nigeria. Journal of Biosocial Science 27.1: 19-30.

Aikhionbare, H. A., Yakubu, A. M., and Naida, A. M. 1989. Mortality pattern in the Emergency Paediatric Unit of Ahmadu Bello University Teaching Hospital, Zaria, Nigeria. Central African Journal of Medicine 35.5: 393-396.

Akpala, C. O. 1993. Perinatal mortality in a northern Nigerian rural community. Journal of the Royal Society of Health I /3.3: I24- 127.

Alao, N., and Adegbola, O.1985. Urbanization, modernization and recent trends in mortality in Africa: a conspectus. Proceedings of the International Population Conference. Adegbola, O. Eds. Florence, Italy 5-I 2 June. 275-286

Amouzou, A., and Hill, K. 2003. Child mortality and socio-economic status in Sub-Sahra Africa. African Population Studies 19. I: I- 12.

Antai, D. 2008. Individual and contextual -level determinants of social inequalities in under-five mortality in Nigeria: differentials by religious affiliation of the mother. World Health \& Population 10.4: 39-52.

20II. Regional inequalities in under-5 mortality in Nigeria: a population-based analysis of individual- and community-level determinants. Population Health Metrics 9.1: 6. doi: 10.1 I86/ 1478-7954-9-6.

Antai, D., and Antai, J. 2008. Individual- and contextual-level determinants of social inequities in under-five mortality in Nigeria: differentials by religious affiliation of the mother. World Health and Population 10.4: 38-52.
Ayeni, O.1985. Geographic and socio-economic differentials characteristic of infant and child mortality in Africa. Proceedings of the International Population Conference. Adegbola, O. Eds. Florence Italy 5-I 2 June. 26I-273

Ayoola, O. O., Orimadegun, A. E., Akinsola, A. K., and Osinusi, K. 2005. A five-year review of childhood mortality at the University College Hospital, Ibadan. West African Journal of Medicine 24.2: 175-179.

Bamgboye, E. A., and Familusi, J. B. 1990. Mortality pattern at a children's emergency ward, University College Hospital, Ibadan, Nigeria. African Journal of Medicine and Medical Sciences 19.2: 127-132.

Bicego, G. T., and Boerma, T. T. 1993. Maternal education and child survival: a comparative study of survey data from 17 countries. Social Science and Medicine 36.9: I207-I 222.

Black, R. E., Cousens, S., Johnson, H. L., Lawn, J. E., Rudan, I., Bassani, D. G., Jha, P., Campbell, H., Walker, C. F., Cibulskis, R., Eisele, T., Liu, L., and Mathers, C. 2010. Global, regional, and national causes of child mortality in 2008: a systematic analysis. Lancet 375: 1969-1987.

Bocquier, P., Madise, N. J., and Zulu, E. M. 20I I. Is there an urban advantaage in child survival in SubSaharan Africa? Evidence from 18 countries in the 1990s. Demography 48: 531-558.

Brockerhoff, M., and Hewett, P. 2000. Inequality of child mortality among ethnic groups in SubSaharan Africa. Bulletin of the World Health Organization 78.2.

Caldwell, J. C. 1979. Education as a factor in mortality decline: an examination of Nigerian data. Population Studies 33.3.395-4I3. . 1990. Cultural and social factors influencing mortality levels in developing countries. Annals of the American Academy of Political and Social Sciences 5 I0: 44-59.

Cleland, J. G., and Van Ginneken, J. K. 1988. Maternal education and child survival in developing countries: search for pathways of influence. Social Science and Medicine 27.12: |357-| 368.

Collet, D. 1994. Modelling survival data in medical research (Ist ed.). London: Chapman \& Hall.

Cox, D. R. 1972. Regression models and life tables. Journal of the Royal Statistical Society B.34: 187220.

Das Gupta, M. 1990. Death clustering, mother's education and determinants of child mortality in rural Punjab, India. Population Studies 44.3: 489505.

Ekanem, E. E., Asindi, A. A., and Okoi, O. U. 1994. Community-based surveillance of paediatric 
deaths in Cross River State, Nigeria. Tropical and Geographical Medicine 46.5: 305-308.

Fayehun, O. 2010. Household environmental health hazards and child survival in Sub-Saharan Africa. DHS Working Papers No. 74. Calverton, Maryland, USA: ICF Macro.

Fayehun, O., and Omololu, O. 20II. Ethnicity and child survival in Nigeria. African Population Studies 25.Supplement I: 92-I I2.

Federal Office of Statistics. 1992. Nigeria Demographic and Health Survey 1990. Federal Office of Statistics and IRD/Macro International, Calverton MD.

Fotso, J. 2006. Urban-Rural differentials in child malnutrition: trends and socio-economic correlates in Sub-Saharan Africa. Health Place I3.I: 205-223.

Franz, J. S., and FitzRoy, F. 2006. Child mortality and environment in developing countries. Population and Environment 27.3: 263-284.

Fuchs, R., Pamuk, E., and Lutz, W. 20I0. Education or wealth: which matters more for reducing child mortality in developing countries? Vienna Yearbook of Population Research 8: 175-199.

Gakidou, E., Cowling, K., Lozano, R., and Murray, C. J. 20I0. Increased educational attainment and its effect on child mortality in 175 countries between 1970 and 2009: a systematic analysis. Lancet 376: 959--974.

Hill, K., and Upchurch, D. M. 1995. Gender differences in child health: evidence from the Demographic Health Surveys. Population and Development Review 21.I: 127-I5I.

Hong, R., Ayad, M., Rutstein, S., and Ren, R. 2009. Childhood mortality in Rwanda: Levels, trends and differentials. Further analysis of the Rwanda Demographic Health Surveys 1992-2007/8. ICF Macro, Calverton, Maryland, USA.

Ikamari, L. D. E. 1995. Explaining regional variation in infant and child mortality in Kenya. Working Papers in Demography 57: I-16.

lyun, B. F. 2000. Environmental factors, situation of women and child mortality in southwestern Nigeria. Social Science and Medicine 5I: 14731489.

Kandala, N. B., Ji, C., Stallard, N., Stranges, S., and Cappucio, F. P. 2007. Spatial analysis of risk factors for childhood mortality in Nigeria. American Journal of Tropical Medicine and Hygiene 77.4: 770779.

Kembo, J., and Van Ginneken, J. K. 2009.

Determinants of infant and child mortality in Zimbabwe: Results of multivariate hazard analysis. Demographic Research 21.13: 367 - 384.

Kuate-Defo, B. 1996. Areal and socio-economic differentials in infant and child mortality in
Cameroon. Social Science and Medicine 42.3: 399420.

Kuate-Defo, B., and Diallo, K. 2002. Geography of child mortality clustering within African families. Health \& Place 8: 93-II 7.

Lavy, V., Strauss, J., Thomas, D., and Vreyer, P. 1996. Quality of health care, survival and health outcomes in Ghana. Journal of Health Economics 15: 333-357.

Lawoyin, T. O. 2007. Infant and maternal deaths in rural south west Nigeria: a prospective study. African Journal of Medicine and Medical Sciences 36.3: 235-24I.

Lay, J., and Robilliard, A.-S. 2009. The complementarity of MDG achievements: The case of child mortality in Sub-Sahara Africa. Policy Research Working Paper 5062: The World Bank.

Library of Congress. 2008. Nigeria Country Profile. Retrieved 02/I I/20 I I, from Library of Congress Federal Research Division http://lcweb2.loc.gov/ frd/cs/profiles/Nigeria.pdf

Luke, B., and Brown, M. B. 2006. The changing risk of infant mortality by gestation, plurality, and race: 1989-199| versus 1999-200I. Paediatrics I / 8.6: 2488 - 2497.

Lykens, K., Singh, K. P., Ndukwe, E., and Bae, S. 2009. Social, economic, and political factors in progress towards improving child survival in developing nations. Journal of Health Care for the Poor and Underserved 20: I37-I 48.

Mabogunje, A. I. 2007 Health challenges of Nigerian urbanization. 9th Benjamin Oluwakayode Osuntokun Memorial Lecture. Ibadan, Nigeria: Benjamin Oluwakayode Osuntokun Trust.

Macassa, G., Ghilagaber, G., Bernhardt, E., and Burstrom, B. 2004. Contribution of household environment factors to urban childhood mortality in Mozambique. East African Medical Journal 8I .8: 408-4I4.

Mahy, M. 2003. Childhood mortality in the developing world: A review of evidence from the Demographic and Health Surveys. DHS Comparative Reports No 4. Calverton, Maryland: ORC Macro.

Manda, S. O. M. 1999. Birth intervals, breastfeeding and determinants of childhood mortality in Malawi. Social Science and Medicine 48: 30I-312.

Mosley, W., and Chen, L. C. 1984. An analytical framework for the study of child survival in developing countries. Population and Development Review 10.suppl: 25-45.

Nakamura, H., Ikeda, N., Stickley, A., Mori, R., and Shibya, K. 20II. Achieving MDG 4 in Sub-Saharan Africa: What has contriuted to the accelerated child mortality decline in Ghana? PLoS ONE 6.3: el 7774. doi: doi: I0.1371/journal.pone.0017774 
Nannan, N., Timaeus, I. M., Laubsher, R., and Bradshaw, D. 2007. Levels and differentials in childhood mortality in South Africa, 1977- 1998. Journal of Biosocial science 39: 613-632.

National Population Commission [Nigeria]. 2000. Nigeria Demographic and Health Survey 1999. Calverton, Maryland: National Population Commission and ORC Macro International. 2004. Nigeria Demographic and Health Survey 2003. National Population Commission and ORC Macro International, Calverton MD. 2009a. National and State Population

Housing Tables: Priority Tables Volume I. . 2006 Population and Housing Census of the Federal Republic of Nigeria. Abuja: National Population Commission. 2009b Nigeria Demographic and Health Survey 2008. National Population Commission and ORC/Macro International, Calverton MD 2009c. Nigeria Demographic and Health Survey 2008. National Population Commission and ORC Macro International, Calverton MD

Ngowu, R., Larson, J. S., and Kim, M. S. 2008. Reducing child mortality in Nigeria: A case study of immunization and systemic factors. Social Science and Medicine 67: 16I-164.

Nuwaha, F., Babirye, J., and Ayiga, N. 20II. Why the increase in under-five mortality in Uganda from 1995 to 2000 ? A retrospective analysis. BMC Public Health II.725.

Omariba, D. W. R., Beaujot, R., and Rajulton, F. 2007. Determinants of infant and child mortality in Kenya: An analysis controlling for frailty effects. Population Research \& Policy Review 26.2: 299-32I.

Rajaratnam, J. K., Marcus, J. R., Flaxman, A. D., Wang, H., Levin-Rector, A., Dwyer, L., Costa, M., Lopez, A. D., and Murray, C. J. 20 I0. Neonatal, post-neonatal, childhood, and under-5 mortality for I87 countries, 1970-2010: a systematic analysis of progress towards Millennium Development Goal 4. Lancet 375: 1988 - 2008.

Rutstein, S. 2005. Effects of preceding birth intervals on neonatal, infant and under-five years mortality and nutritional status in developing countries: evidence from the demographic and health surveys. International Journal of Gynecology \& Obstetrics 89: 7-24.

Rutstein, S., Ayad, M., Ren, R., and Hong, R. 2009 Changing health conditions and decline of infant and child mortality in Benin. Calverton, Maryland, USA.: ICF Macro.

Rutstein, S. O. 2000. Factors associated with trends in infant and child mortality in developing countries during the 1990s. Bulleting of the World Health Organization 78.10: 1256-1 270.

Sastry, N. 1997. A Nested Frailty Model for Survival Data, With an Application to the Study of Child Survival in Northeast Brazil. Journal of the American Statistical Association 92.438: 426-435. 2004. Urbanization, development and under-five mortality differentials by place of residence in Sap Paulo, Brazil, 1970-1991. Demographic Research Special Collection 2.14.

Satterthwaite, D., Hart, R., Levy, C., Mitlin, D., Ross, D., Smith, J., and Stephens, C. 1996. The environment for children. London: UNICEF, Earthscan.

Ssewanyana, S., and Younger, S. D. 2007. Infant mortality in Uganda: Determinants, Trends and the Millenium Development Goals. Journal of African Economies 17.I: 34-6I.

UBEC. (20I2). Universal Basic Education Commission, Nigeria, 24/07/2012, from http:// ubeconline.com/about_ubec.html

UNICEF. 20I0. Monitoring the situation of children and women. Child mortality statistics overview. www.childinfo.org/mortality_overview

United Nations Development Programme. 20I I. Human Development Report 201 I. Retrieved 02/ I I/20I I, from UNDP http://hdrstats.undp.org/ images/explanations/NGA.pdf

Uthman, O. A., Uthman, M. B., and Yahaya, I. 2008. A population-based study of effect of multiple birth on infant mortality in Nigeria. BMC Pregnancy Childbirth 8: 4I. doi: I0.I I86/I47I2393-8-4I

Victora, C. G., Huttly, S. R., Fuchs, S. C., and Olinto, M. T. A. 1997. The role of conceptual frameworks in epidemiological analysis: a hierachical approach. International Journal of Epidemiology 26.1: 224-227.

Vittinghoff, E., Glidden, D. V., Shiboski, S. C., and McCulloch, C. E. 2004. Regression methods in Biostatistics: linear, logistic, survival and repeated measures models. New York: Springer.

Worldbank. (20I2). Education Statistics: Nigeria. Education MDG monitor Retrieved 24/07/2012, from http://go.worldbank.org/KHYE9TME80 